\title{
MATERNAL HEALTH CARE UTILIZATION IN RURAL FIELD PRACTICE AREA OF DR. PSIMS\&RF, KRISHNA DISTRICT, ANDHRA PRADESH, SOUTH INDIA
}

\author{
Sree Karuna Murthy Kolli1, Bhaskari Kolli², Harika Surabathula ${ }^{3}$ \\ ${ }^{1}$ Associate Professor, Department of Community Medicine, GVPHC \& MT, Visakhapatnam, Andhra Pradesh, India. \\ ${ }^{2}$ Assistant Professor, Department of Community Medicine, Guntur Medical College, Andhra Pradesh, India. \\ 3Internee, Dr. PSIMS \& RG, Chinoutpalli, Andhra Pradesh, India.
}

ABSTRACT

\section{BACKGROUND}

Maternal mortality and morbidity continue to be high despite the enormous inputs and efforts imposed through National Health Programmes, to achieve good results for the fifth goal of Millennium Development. There has been very little improvement in the institutional deliveries from NFHS-I (26.1) to NFHS-III (40.8). Underutilization of the Maternal Health Services might be one of the causes for this slow progress.

Aims and Objectives-

1. To assess the proportion of women receiving the recommended antenatal care.

2. To know the proportion of women who received skilled care during childbirth.

3. To study the knowledge and practice of different family planning methods.

\section{MATERIALS AND METHODS}

Study Design- Community based cross sectional study.

Study Population- Mothers of infants.

Study Setting- Three villages were selected by simple random technique from the 9 villages of rural field practice area of Dr. PSIMS\&RF. All the eligible mothers for the study (235), in those villages were interviewed using pretested structured questionnaire. Data thus collected was compiled and analysed.

Study Period- October-December 2014.

\section{RESULTS}

Of the 235 women, $11.06 \%$ are teenage pregnancies, $94.46 \%$ had at least one antenatal checkup during pregnancy. Only $53.19 \%$ are consuming iron and folic acid tablets. Majority of them are institutional deliveries (94.2\%). 57\% have undergone permanent family planning methods of which only $2 \%$ were vasectomies. 63 of the study participants are not using any kind of family planning.

\section{CONCLUSION}

Though the utilization of antenatal and intranatal care services has improved, there is still a lacuna in utilization of different family planning methods. In spite of increased availability of family planning services, most of them are not practicing to the expected level. This gap can be reduced by improving the accessibility of the RCH services and through behaviour change and communication for transforming knowledge into practice.

\section{KEY WORDS}

Maternal Health, Antenatal Care, Institutional Delivery, Family Planning.

HOW TO CITE THIS ARTICLE: Kolli SKM, Kolli B, Surabathula H. Maternal health care utilization in rural field practice area of dr. PSIMS\&RF, Krishna District, Andhra Pradesh, South India. J. Evolution Med. Dent. Sci. 2018;7(51):5407-5410, D0I: $10.14260 /$ jemds/2018/1197

\section{BACKGROUND}

According to the World Health Organization (WHO), eight million of the estimated 210 million women who become pregnant each year experience life-threatening complications. ${ }^{1}$ India, with more than 1.21 billion population, managed to reduce the maternal mortality ratio (MMR) from 600 per 100000 live births in 1990 to 200 per 100000 live births in $2010 .^{2}$

'Financial or Other Competing Interest': None.

Submission 23-11-2018, Peer Review 05-12-2018,

Acceptance 08-12-2018, Published 17-12-2018.

Corresponding Author:

Dr. Bhaskari Kolli,

Assistant Professor,

Department of Community Medicine,

Guntur Medical College, Andhra Pradesh, India.

E-mail: bhaskarikolli@gmail.com

DOI: 10.14260/jemds/2018/1197

\section{(c) (i) $\$$}

Maternal mortality and morbidity continue to be high despite the enormous inputs and efforts imposed through reproductive and child health Programme to improve the maternal and child health, to achieve good results for the goal 5 of MDGs. The entire focus of the Government of India regarding reproductive health services has been on ANC, PNC and delivery care, not only to the combat with maternal and child death rates, but also to make efforts for a safe delivery and a healthy outcome to pregnancy. Since the last four decades, the Government of India has been focusing on women and child health by implementing various programmes like the Maternal and Child Health (MCH) programme, the Child Survival and Safe Motherhood (CSSM) programme, the Janani Suraksha Yojana (JSY) under the National Rural Health Mission (NRHM) and the Integrated Child Development Service (ICDS). These long-term efforts have resulted in the reduction of maternal and child mortality 
in India. It is well established that the majority of maternal deaths may be prevented by providing basic maternal health services to women. ${ }^{3}$ There has been a very little improvement in the institutional deliveries between NFHS-I (26.1) ${ }^{4}$ to NFHS-III (40.8). ${ }^{5}$ Underutilization of the Maternal Health Services might be one of the causes for this slow progress. Utilization of maternal health services includes their utilization of any reproductive health services, including Antenatal care (ANC), post-natal care (PNC) and delivery care facilities and the family planning practices. The visits being a part of normal antenatal care services should begin with the confirmation of pregnancy and continue at an interval of four weeks through the first seven months and then two weeks until the delivery. ${ }^{6}$ However, in India, under the RCH, a minimum of four visits has been considered as a modest goal. It is well known that the utilization of antenatal care services significantly reduces the maternal morbidity and mortality rates because during these medical care visits the information provided includes the advice on the correct diet, provision of iron and folic acid tablets and tetanus injections to pregnant women. ${ }^{7}$ The present study is an effort to assess the utilisation pattern of maternal health care services (ANC, PNC, delivery care and family planning practices ) among mothers of infants in rural field practice area of DR. PSIMS\&RF

\section{Objectives}

1. To assess the proportion of women receiving the recommended antenatal care during pregnancy.

2. To know the proportion of people received skilled care during childbirth.

3. To assess the proportion of women receiving the recommended post-natal care.

4. To study the practice of different family planning methods.

\section{MATERIALS AND METHODS}

The present study was a community based cross sectional study in a villages of rural field practice area of Department of Community Medicine, Dr. PSIMS\&RF, Chinoutpalli. The 9 villages under the field practice area were numbered 1 to 9 and 3 villages were selected by lottery method of simple random technique. In those three villages all the married women who are mothers of infants were interviewed using pretested structured questionnaire including identification data, socio-demographic profile, details of antenatal care, delivery, postnatal care and family planning measures. At least three visits were made to include all the women who could not be contacted in the first visit. Oral consent was obtained before starting of the interview. With this the final total sample size came out to be 235 . The study was conducted from October 2014 to December 2014. The data thus obtained was entered in SPSS version 16 and presented in the form of proportions, and graphs.

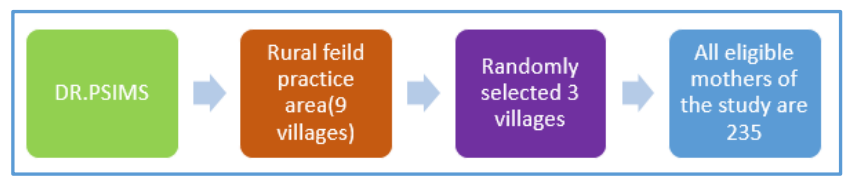

\section{RESULTS}

Socio demographic profile of the women who have participated in the study is as follows (Table -1). Among the 235 women who were interviewed there are about $11 \%$ of them who are below 20 years of age depicting teen age pregnancies. Caste plays $\mathrm{n}$ important role in health care practices because the differences in the customs. Here in the study population Out of the 235 , there are about $32 \%, 44 \%$, $16 \%$ and $8 \%$ belong to the OCs, BC, schedule cast and schedule tribe community respectively. Education of the women helps them in understanding and practicing the maternal health care services in an effectual way to improve their and their child's health. Out of the 235 women there are about 33 of them who are illiterate ie (14\%) and 94 of them have attended primary schooling ie. (40\%); 108 of them had completed primary schooling and entered higher education i.e. $(46 \%)$.

Antenatal care utilization among the women (Table-2) shows that more than half $(62 \%)$ of them had more than 3 antenatal visits. But there about $6 \%$ of them have not visited for prenatal checkup at least once, $3 \%$ of them have not received even a single dose of TT Immunization, About 3.41\% have not received iron folic acid tablets at all. This depicts the unmet need for maternal care utilizations.

Delivery care practices show that still 11 (5\%) of them had delivered at home this has to be concentrated even though there is much increase in institutional deliveries 224 (95\%) private hospitals are taking a maximum share of hospital deliveries 156 (66\%) compared to government hospitals 68 (29\%) (Fig. 1)

Out of 235 study participants, 163 (69\%) of them received post-natal care PNC in 48 hours; nearly half of the participants, that is 125 (53\%) of them received minimum of six postnatal visits by 6 weeks and the percentage of people who received supplementary nutrition from Anganwadi are about 29\%. (Table-3)

Regarding practicing of family planning services, 135 (57\%) of them had undergone tubectomy and vasectomy (55\% and 2\% respectively).out of the remaining 101 study participants, $13(! 2 \%)$ of the are using condoms as temporary family planning method and 25 (24\%) were using oral pills. More than half of them that is $63(62 \%)$ were not using any of the family planning methods. (Table -4 )

\begin{tabular}{|c|c|c|}
\hline \multicolumn{2}{|c|}{ Socio Demographic Factors } & $\begin{array}{c}\text { Frequency } \\
\text { (Percentage) }\end{array}$ \\
\hline \multirow{3}{*}{ Age (N=235) } & $<20$ years & $26(11 \%)$ \\
\cline { 2 - 3 } & $20-30$ years & $197(84 \%)$ \\
\cline { 2 - 3 } & $>30$ years & $12(5 \%)$ \\
\hline \multirow{4}{*}{ Caste $(\mathrm{N}=235)$} & OC & $76(32 \%)$ \\
\cline { 2 - 3 } & BC & $103(44 \%)$ \\
\cline { 2 - 3 } & SC & $38(16 \%)$ \\
\cline { 2 - 3 } Education of the & ST & $18(8 \%)$ \\
\cline { 2 - 3 } Participant (N=235) & Illiterate & $33(14 \%)$ \\
\cline { 2 - 3 } & Primary & $94(40 \%)$ \\
\hline \multicolumn{2}{|c|}{ Table 1. Distribution of Study Participants on } \\
Sociodemographic Profile \\
\hline \multirow{2}{|c|}{}
\end{tabular}




\begin{tabular}{|c|c|c|}
\hline \multicolumn{2}{|c|}{ Antenatal Care Utilization } & $\begin{array}{c}\text { Frequency } \\
\text { (Percentage) }\end{array}$ \\
\hline \multirow{2}{*}{$\begin{array}{c}\text { Number of antenatal } \\
\text { visits (N=235) }\end{array}$} & None & $14(6 \%)$ \\
\cline { 2 - 3 } & $<3$ ANC visits & $75(31.90 \%)$ \\
\hline \multirow{2}{*}{$\begin{array}{c}\text { TT immunization } \\
(\mathrm{N}=235)\end{array}$} & $\begin{array}{c}\text { At least one } \\
\text { TT } / \text { booster }\end{array}$ & $228(97 \%)$ \\
\cline { 2 - 3 } & Not received TT & $7(3 \%)$ \\
\hline \multirow{2}{*}{$\begin{array}{c}\text { Anaemia prophylaxis } \\
\text { (N=235) }\end{array}$} & $\begin{array}{c}\text { Received } \geq 100 \text { IFA } \\
\text { tablets }\end{array}$ & $122(51.91 \%)$ \\
\cline { 2 - 3 } & $\begin{array}{c}\text { Received }<100 \text { IFA } \\
\text { tablets }\end{array}$ & $105(44.68 \%)$ \\
\cline { 2 - 3 } & $\begin{array}{c}\text { Not received IFA } \\
\text { tablets }\end{array}$ & $8(3.41 \%)$ \\
\hline \multirow{2}{*}{ Table 2. Distribution of Study Participants on Antenatal } \\
Care Utilization
\end{tabular}

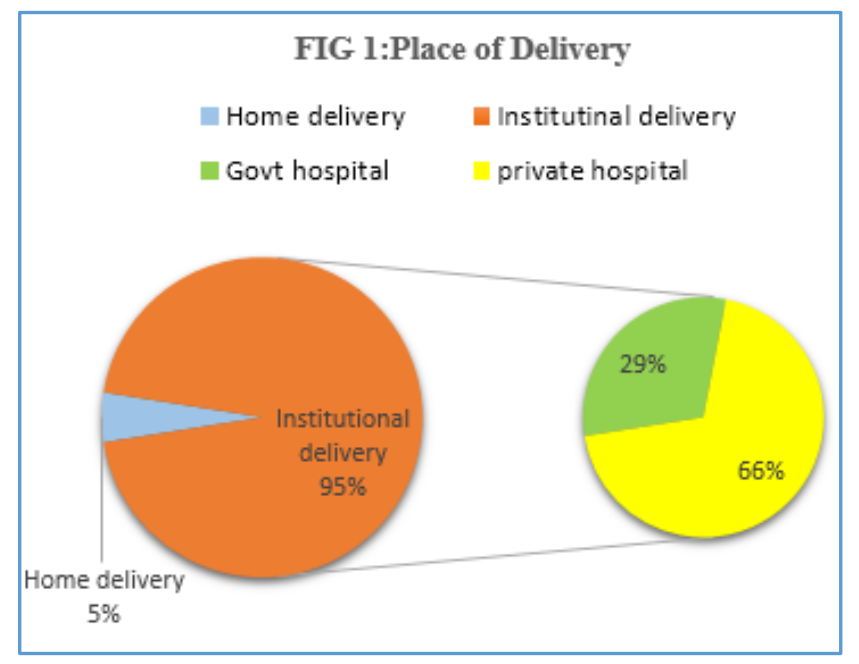

\begin{tabular}{|c|c|}
\hline Post Natal Care & $\begin{array}{c}\text { Frequency } \\
\text { (Percentage) }\end{array}$ \\
\hline $\begin{array}{c}\text { Post Natal Care within 48 hours after } \\
\text { delivery (N=235) }\end{array}$ & $163(69.36 \%)$ \\
\hline Post Natal care with min 6 visits (N=235) & $125(53.19 \%)$ \\
\hline $\begin{array}{c}\text { Supplementary nutrition received from } \\
\text { Anganwadi (N=235) }\end{array}$ & $68(28.90 \%)$ \\
\hline $\begin{array}{c}\text { Table 3. Distribution of Study Participants on Post Natal } \\
\text { Care Utilization }\end{array}$ \\
\hline
\end{tabular}

\begin{tabular}{|c|c|c|}
\hline \multirow{2}{*}{$\begin{array}{c}\text { Practice of permanent } \\
\text { methods (N=235) }\end{array}$} & $\begin{array}{c}\text { Frequency } \\
\text { (Percentage) }\end{array}$ \\
\cline { 2 - 3 } & Tubectomy & $101(43 \%)$ \\
\cline { 2 - 3 } & Vasectomy & $4(2 \%)$ \\
\hline \multirow{2}{*}{$\begin{array}{c}\text { Practice of temporary } \\
\text { methods (N=101) }\end{array}$} & Nil & $63(62 \%)$ \\
\cline { 2 - 3 } & Condom & $13(12 \%)$ \\
\cline { 2 - 3 } & Oral pills & $25(24 \%)$ \\
\hline \multirow{2}{*}{$\begin{array}{c}\text { Table 4. Distribution of Study Participants on Family } \\
\text { Planning Practicing Measures }\end{array}$} \\
\hline
\end{tabular}

\section{DISCUSSION}

Access to the basic medical services during antenatal, delivery and post-natal period reduces maternal mortality to a greater extent. Utilization of the services provided through a network of health centers, as well as home visits by health workers remain to be poor in India. 8

The present study most women $63 \%$ received antenatal care in equal to or more than 3 visits antenatal care. Das observed $22(37.3 \%)$ paid equal to and above four antenatal visits. ${ }^{9}$ Dabade et al showed 110 respondents (53.4\%) had paid three or more than three antenatal visits and 12 (5.8\%) did not pay any antenatal visit. ${ }^{10}$ According to NFHS-3 survey (2005-06) 83.3\% of rural women paid at least three antenatal care visits in Andhra Pradesh. This shows that the women in the present study have lesser utilization of antenatal care visits. In the present study, $51 \%$ of the last births received more than 100 IFA tablets compared to that of NFHS -3 survey 77 percent of their last births, mothers received iron and folic acid supplements (IFA). ${ }^{4}$

Despite the availability of health institutions in India, pregnant women are still. Delivering at home. The present study showed $5 \%$ home deliveries. This is much lower when compared to the study done by Pund et al rural Maharashtra. 11 by Ranjan et al in rural Aligarh (10\%) this shows an improvement in institutional deliveries.

Post-natal care services were received within 48 hours of delivery by nearly two third (69.3\%) of the women. Malik et al (2015) revealed that $2.7 \%$ of mothers did not receive any post-natal visit and $62.8 \%$ of subjects were received 3 or more PNC visits. ${ }^{12}$

Among the women who were practicing family planning two third of them have adopted permanent methods and among them tubectomy was the most common method. Vasectomy was adopted by only $4 \%$ of the permanent methods. This was similar NFHS-3.

\section{CONCLUSION}

From the observations of the present study, though there has been an increase in institutional deliveries, there is a lot of gap in the utilization of antenatal, postnatal and family planning services. This can be improved by continuous contact of health workers with the pregnant women right from their conception. The unmet need of family planning has to be addressed. This can be achieved by behaviour changes, communication and active community participation.

\section{REFERENCES}

[1] WHO 2009. Achieving Millennium Development Goal 5: target $5 \mathrm{~A}$ and $5 \mathrm{~B}$ on reducing maternal mortality and achieving universal access to reproductive health, in briefing note on achieving Millennium Development Goal (MDG) 5, 2009: p. 2. WHO reference number: WHO/RHR/09.06

http://www.who.int/reproductivehealth/ publications/monitoring/rhr_09_06/en/index.html

[2] Singh PK, Kumar C, Rai RK, et al. Factors associated with maternal healthcare services utilization in nine high focus states in India: a multilevel analysis based on 14, 385 communities in 292 districts. Health Policy and Planning 2014;29(5):542-59.

[3] Ronsmans C, Graham WJ, Lancet Maternal Survival Series Steering group. Maternal mortality: who, when, where and why. The Lancet 2006;368(9542):1189 200.

[4] National family health survey (NFHS-1) 1992-93. International Institute for Population Sciences (IIPS) and Macro International 2009.

http://www.rchiips.org/nfhs/nfhs1.shtml 
[5] National family health survey (NFHS-3) 2005-06. International Institute for Population Sciences (IIPS) and Macro International, 2009. http://www.rchiips.org/nfhs/nfhs3.shtml

[6] Agarwal P, Singh MM, Garg S. Maternal health care utilization among women in an urban slum in New Delhi. IJCM 2007;32(3):203-5.

[7] Aditi I. Women's Access to Health Care, Section C, 3.7 of the Women's Health Development, Country Profile, India: CEHAT Publication 1998: p. 425-47.

[8] Kumar R, Singh MM, Kaur A, et al. Reproductive health behaviour of rural women. J Ind Med Assoc 1995; 93(4):129-31, 128.

[9] Das R, Amir A. Utilization and coverage of services by women of Jawan Block in Aligarh. Indian J Community Med. 2001;26(2):94-100.
[10] Dabade KJ, Dabade SK, Khadilkar HA. A study on utilization of maternal health care services in rural area of Aurangabad District, Maharashtra. Natl J Community Med 2013;4(4):579-83.

[11] Pund SB, Kuril BM, Doibale MK, et al. Study of the changing trends in place of delivery in rural women in relation to pre and post NRHM period in Paithan, Aurangabad, Maharashtra. Int J Community Med Public Health 2017;4(7):2356-60.

[12] Malik JS, Kalhan M, Punia A, et al. Utilization of health services under Janani Suraksha Yojna in rural Haryana. Int J Med \& Public Health 2013;3(3):176-9. 